Journal of Education and Vocational Research

Vol. 3, No. 7, pp. 204-215, July 2012 (ISSN 2221-2590)

\title{
Investigating Attitudes towards Financial Literacy in Schools: An Impact Study
}

\author{
Noi Keng $\mathrm{KOH}$ \\ National Institute of Education, Nanyang Technological University, Singapore \\ noikeng.koh@nie.edu.sg
}

\begin{abstract}
The global economic downturn has highlighted the damaging impact of financial illiteracy on individuals, families, communities and entire nations. The need to teach people how to spend, save, invest, borrow and manage money wisely has become more important than ever. It has also raised questions about what it takes to effectively engage people and change their financial behavior. This study is part of a larger study in Singapore schools to study the impact of an initiative to equip teacher's with pedagogical skills and knowledge to integrate financial literacy messages in day-to-day lessons and foster a socially responsible attitude towards managing money to create a financially sustainable society. This study provides insights into how financial education can be integrated into classroom lessons in schools to deal with challenges that living in modern society presents.
\end{abstract}

Key words: Financial education, Managing money, financial literacy, pedagogy, attitude

\section{Introduction}

Financial literacy (FL) is gradually becoming a necessary part of successful socialization, important for both individual well-being and smooth functioning of social and economic institutes. To inculcate the habits connected to handling financial resources successfully, it is important to start teaching such habits from a young age in diverse student populations. The Financial Literacy Hub at the National Institute of Education Singapore, funded by Citi Foundation, carries out targeted pedagogical interventions that aim to introduce students to the principles of financial management from an early age. The Hub has adopted a "trickle-down" approach to financial literacy instruction, when at first a group of teachers is invited to participate in personal finance seminars and pedagogical workshops focused on FL instruction. Subsequently, the Hub helps these teachers to design and implement FL-rich lessons for secondary students in their respective school. The present study reports key findings from a FL intervention project that was designed for students from middle- and working-class families. It is shown that such interventions are invaluable in enabling the students to acquire conceptual knowledge and, with time, translate this knowledge into well-trained habits.

\section{Background of the Study}

The present study is a continuation of the instruction-cum-research program investigating a possibility of successful FL instruction for students from diverse socio-economic backgrounds. Previously accumulated evidence suggests that some students may show certain awareness of the importance of financial management. This awareness can result from exposure to the issues relating to money management through family talk, daily interaction with parents, relatives and peers. It is an open question, however, how well conceptually such early knowledge of the rudiments of financial literacy entrenched is. More importantly, it is quite clear that this fragmentary knowledge resulting from social learning without scaffolding cannot be deemed sufficient to deal with challenges that living in modern society presents. As the recent financial crisis has highlighted, even more financially perceptive people are susceptible to losing their savings in ill-advised investments. Therefore, it becomes important to expose students to systematic FL instruction at a younger age to equip them with necessary knowledge and right attitudes to saving, budgeting and investing money. The main difficulty of successful FL instruction for this student population lies in the need to enhance students' positive attitudes towards FL and enrich them with knowledge they find relevant and useful. Therefore, a FL literacy intervention for such students should start from the basics but develop gradually into a program that is both conceptually challenging and engaging. At the same time, FL interventions for these student populations should provide a firm basis for further conceptual development in the sphere of FL, as 
well as values education. The general approach to FL instruction can be framed in pedagogical terms as well as in terms of learning outcomes. From the pedagogical point of view, this approach stems from the understanding of the similarities and differences between "spontaneous", "everyday" concepts and "scientific" ones (Vygotsky, 1978). Deeper, more analytic understanding of the subject matter of FL uses everyday understanding of money matters acquired from interactions with grown-ups and peers, and adds another level of understanding that is conceptually coherent and socially grounded. This is achieved through using the Zone of Proximal Development (ZPD) where the actual content taught is slightly above the current level of students' understanding 0 p. cit.). Such broadly constructivists 'perspective finds a direct counterpart in Adams \&Wallace's (1990) approach, which they term 'TASC' ('Thinking Actively in a Social Context') framework. These authors emphasize affective and cognitive factors in acquiring and generating new knowledge and skills. Among the affective factors underscored in this approach is a need for the learner to understand the importance of systematic exploration of the subject matter. Among the cognitive and Meta cognitive factors are awareness of incomplete knowledge and interplay of critical, analytic and creative thinking. TASC prioritizes experiential learning, whereby new experiences are built on the previous ones and application of the new knowledge is deemed most important.

In terms of learning outcomes, Jonassen \& Tessmer (1996/7) proposed a taxonomy that is related to the constructionist approach: in addition to declarative and structural knowledge, situated problem solving (identifying problem space $\rightarrow$ decomposing problems $\rightarrow$ hypothesizing solutions $\rightarrow$ evaluating solutions), selfknowledge (articulating prior knowledge, socio cultural knowledge and personal strategies) and reflective self-knowledge (being aware of one's own cognitive weaknesses) are highlighted. The pedagogical intervention consisted of a series of lectures/presentations and project work covering a wide range of topics, from differentiating needs vs. wants to budgeting and credit. The FL knowledge was adapted to the students' level of understanding. The goal of the intervention was not only to impart practically important knowledge and skills, but also to try to enhance the students' understanding of, and positive attitude towards, FL. The overarching objective was to set the students on the path of life-long learning and, possibly, real behavioral change as far as FL is concerned. The study focused on assessing knowledge and attitudes of the student before they start on the FL program and the learning outcomes during and after the program.

\section{Methodology}

The study used quantitative and qualitative method to obtain a richly detailed picture of the program's impact but only the qualitative findings are reported in this paper. Qualitative data was collected during focus group discussions (FGDs). This is a form of qualitative research where a group of people goes through a semistructured interaction between themselves and the researcher answering questions on their conceptual understanding of as well as attitudes towards and perceptions of a thing or a problem. FGDs are especially useful in the circumstances where there are uncertainties and multiple interpretations of the same set of questions. The format of the FGD affords a much deeper probing than a simple survey. In addition, FGDs tend to produce socially and conceptually contextualized data often weaved into short narratives (Warr, 2005). 120Secondary 2 students participated in FGDs. They were interviewed in separate groups three times during the study. The first FGD was conducted before the start of the pedagogical intervention, whereas the other two sessions were conducted after the students were exposed to a substantial amount of FL teaching. The themes highlighted during the sessions differed between the first, second and third FGDs. The earlier FGDs focused more on conceptual knowledge and attitudes towards FL. The later sessions probed the students' assessment of their learning experience, changes in their attitude towards FL and conceptualizing actual and possible application of the knowledge acquired during the FL course. Additionally, an interview with three teachers who were responsible for the implementation of the FL intervention was conducted after the FL program was carried out to triangulate the preliminary findings from student FGDs.

\section{Results and Discussion}

Cognitive and Behavioral Dimensions of FL: Understanding of FL Concepts and Budgeting: The theme of FL and budgeting was presented to the students from both cognitive and affective angles. Overall, before the intervention the students showed an overly broad and not sufficiently detailed understanding of FL during the first FGD sessions. They tended to give general answers with little or simply profess ignorance: 
I: What is financial literacy?

- S1: no clue.

- S2: something to do with money.

- S3: something to do with money.

- S4: something to do with money.

- S5: it is about financial planning.

- I: so what is financial planning?

- S5: It is about planning money well and using it wisely.

- FGD-1-1

I: What is financial literacy? What do you understand about financial literacy, your own view?

- S1: I don't know anything

- S2: means involve money

- S3: blank

- S4: don't know

- S5: don't know

- FGD-2-1

I: What do you think financial literacy is? You see the word "financial literacy", what does it mean?

- S1: Something has to do with money.

- S2: something has to do with money. Anything else come into your mind, pop into your mind? What is financial literacy?

- S1: money.

- I: okay, so [name], what you think is financial literacy?

- S2: I think... how to handle money.

- I: how to handle money. So what? How to hold the money?

- S3: no, how to save.

- FGD-3-1

I: what is financial literacy?

- S1: money

- S2: nothing but money. Literacy also money

- S3: lack of money

- S4: money talk

- S5: manage money

- FGD-4-1

Such limited understanding survived further into the program. However, after an initial exposure to the FL course, the students showed a more systematic conceptualization of FL matters, especially in relation to financial planning:

I: okay, what you know about financial literacy? What is financial literacy?

- S1: I know financial literacy is more about money and something about saving.

- I: okay

- S2: Erm, about money.

- I: About money. Anything more about money? Okay.

- S3: About money how to use it and how to spend it wisely

- I: Okay.

- S4: About money.

- S5: About saving and spending money.

- FGD-1-2

I: Can you now share with me, what is financial literacy? 
- S1: Financial Literacy is financial planning.

- I: Planning... okay next

- S2: is like how to ...learn how to save up your money and spend wisely.

- I: Okay.

- S3: know how to use you money well.

- I: How... define how you use your money well?

- S3: By not spending all the money that we have.

- I: Okay ...alright.

- S4: spend wisely.

- I: Spend wisely. Alright.

- S5: Plan your... money correctly

- FGD-2-2

It is clear from the transcripts that the term "financial literacy" is not part of the vocabulary students' everyday concepts. After exposure to the FL program, the students became more adept in organizing their previous knowledge of money management and the knowledge they gained into a more articulated network of concepts. However, cognitive gains were less pronounced during the initial phase of the program as it took time for the students to assimilate the new knowledge into their previously used cognitive schemata. Discussion of budgets and budgeting in the pre-intervention FGDs showed a similarly limited understanding in cognitive terms. Those students who were able to formulate coherent answers tended to associate budget with relative affordability of an item or with a spending limit:

I: Now, what is a budget?

- S1: It's like a certain amount which you can use for something

- I: An amount meaning?

- S1: It is like an amount of money you spend.

- Interviewer: So, what is a budget to you?

- S2: For example, when I go shopping, I set my budget at $\$ 100$ and i cannot go beyond that.

- S2: It is something you cannot go beyond.

- I: Do not worry; just tell me what you understand by a budget.

- S2: It is something you need when you go shopping to make sure you will not overspend.

- S3: It is like a limit. We cannot overspend.

- FGD-1

I: What do you understand is a budget?

- S1: Something within our own cost

- S2: The money we own or spend

- S3: Budget is like the money we want to spend

- S4: Spend maximum cost

- S5: Not to overspend

- FGD-2

I: what is budget?

- $\quad[\ldots]$

- S1: Cheap!

- I: Cheap ar, budget means cheap. Ok, anything else other than cheap? Budget.

- S2: Not expensive.

- I: Not expensive, ok. Come, [name].

- S3: I don't know

- $\quad$ FGD-3

I: Do you know what a budget is? 
- S1: when you buy something, take note of the price. It is like how much you have and how much to spend.

- S2: it means cheap, can buy.

- S3: it is a limit as to how much to spend.

- I: do you limit yourself?

- S3: yes

Interviewer: so what is a budget?

- S5: affordable. It means everyone can get, not too expensive.

- $\quad$ FGD-4

Thus, a dynamic nature of budgeting and its relation to long-term goals were still not understood by the students who were not exposed to the FL intervention yet. Interestingly, when prodded to think about spending and budgeting in behavioral/procedural terms, some students showed more awareness of the dynamics of saving and spending:

I: How do you budget?

- S1: I write down things i want to buy and beside it, note down the amount i want to spend on buying each item.

- S2: I will think twice before buying and ask myself if it is a necessity. I would probably note down the more important things too.

- S3: I will write down the most important thing first, like those items I really need. I will not buy the things i least need first. For example, buy the things that you have wanted to get for months and years.

- $\quad$ FGD-1

I: Do you know what a budget is?

- S1: when you buy something, take note of the price. It is like how much you have and how much to spend.

- $\quad$ FGD-4

At the same time, the students showed understanding of the difference between wants and need:

- S1: i want a new cell phone.

- I: a want or a need?

- S1: i can still use my phone just that it is a little lag in its functions. I think i need new shoes. need is something you require in your daily live, for example, toothpaste

- I: give me examples of a need and a want.

- S2: when there are holes in your shoes, a need is a pair of shoes. When you want a cell phone when you already have many of them that is a want.

- $\quad$ FGD-4

However, such rudimentary knowledge of FL basics did not seem to form a conceptually coherent approach to money matters. Instead, the students tended to focus on decontextualized basic skills. In addition, behavioral self-reports generated during the pre-intervention seemed to confirm that the students would not necessarily reason in terms of creating a budget or wants vs. needs when they were faced with a money management task:

I: Do you find out before you buy something? Do you compare price?

- S1: No

- I: you just go out and shop, and then you just buy?

- S1: Mmm.

- I: Ok, what about you?

- S2: See the price first lah, if can afford then we will buy.

- I: Ok, so if cannot afford then what will you do? 
- S2: Cannot afford... Ask for more, from parents.

- I: Oh, ok, ok, alright. What about you?

- S3: If the price is right then buy, if it is not right then forget it.

- I: Ok

- S4: I got compare, see whether some shops got sell the same things and go and compare it, whether is it cheaper then go to the shop and buy, the shop that is cheaper then buy.

- I: Ok

- S5: No, I do not compare.

- $\quad$ FGD-2

After initial exposure to the FL course, the students started showing a much more richly articulated concept of FL. Most notably, they linked FL with financial planning:

- I: Can you now share with me, what is financial literacy?

- S1: Financial Literacy is financial planning.

- I: Planning... okay can, next, name first.

- S2L: Em...L... is like how to ...learn how to save up your money and spend wisely.

- I: Okay.

- S3: I'm N. Em... know how to use you money well.

- I: How... define how you use your money well?

- S3: By not spending all the money that we have.

- I: Okay ...alright.

- S4: Er...E... spends wisely.

- I: Spend wisely. Alright.

- S5: Plan your... money correctly

- FGD-2-2

The same was true, at least for some students, of the understanding of budgeting. Most importantly, the students linked budgeting to wants vs. needs to achieve a dynamic understanding of the matter:

I: can you share with me what do you understand by what is a budget?

- S1: A budget is to focus on a ... point for the money and not to overspend it.

- I: Okay.

- S2: And a budget is not to overspend and just like for example if you have a list of things that you want to buy just stick to it and stick to the price.

- I: Stick to the price... Alright.

- S3: Don't over spend like what's beyond your needs.

- I: Okay.

- S5: Not to overspend.

- FGD-2-2

It is more difficult to weave these concepts into everyday experience, as many students self-report little behavioral change after a short exposure to the FL intervention:

I: I mean your knowledge and your attitude towards spending your own money and managing your own money before and after the lesson, has it changed?

- S1: Not... erm I didn't really learn anything from the lesson but it's like from parent's lah.

- I: You learn from parents?

- S1: Yah like check the prices first before you buy. Think before you buy.

- I: So that is before or after the lesson?

- S1: Before.

- I: Even before the lesson it has been done?

- S1:Yah. 
I: So now, after the lesson, are you more conscious about checking prices before buying anything?

- S1 I'm already quite conscious.

- I: Already quite conscious. Okay can.

- S2: Erm, I think the financial literacy is like knowledge for me. In addition, yah.

- I: So has your attitude and your knowledge changed about you managing your own money before and after?

- S2: No.

- I: No. How come?

- S2: It's just like information.

- FGD-2-2

In contrast to this, FGDs conducted after the program had been wrapped up showed clear knowledge gains. The students were able to skillfully construct plausible and detailed scenarios involving buying a present for their friend, planning their expenditure they started working and long-term financial planning for a married household. Most importantly, they showed impressive conceptual sophistication in specifying how budgeting was to be conducted: I: So now happily married. Your pay also increases now $\$ 5000$. You have your own house, you also have a car, and you have two kids. These two kids are already going to primary school. Therefore, your $\$ 5000$ can you share with me how you break down the money. You have not fully paid for the house; you have not fully paid for the car. Your wife decided to stay at home and take care of the children. Therefore, your wife is not working.

- S1: $\$ 200$ on each kid, $\$ 400$ on the kids. $\$ 600$ for house bills. $\$ 1000$ for the car. $\$ 500$ I give my mother. $\$ 500$ for my savings, $\$ 1000$ gives my wife, $\$ 500$ on food, $\$ 500$ do charity.

- S2: $\$ 1700$ for house and car, $\$ 500$ for each kid, $\$ 300$ for savings, $\$ 800$ for parents, $\$ 1200$ for my bills, food.

- S3: $\$ 2000$ for car and house. $\$ 500$ for kids, $\$ 500$ save, $\$ 1000$ give wife, $\$ 500$ give to parents, $\$ 500$ for daily spending.

- S4: $\$ 1500$ for car and house, $\$ 1500$ for bills, food, $\$ 600$ for children, $\$ 700$ for parents, $\$ 700$ for other things.

- S4: $\$ 200$ each for children, $\$ 600$ for daily needs, $\$ 2000$ to pay installments all these, $\$ 1000$ gives parents, the other $\$ 1000$ for bills all these.

- $\quad$ FGD-4-3

The students also reported a change in their behavior concerning expenditure and budgeting due to the knowledge acquired while taking the FL course:

I: Alright. So now, how will you all spend or save your money?

- S1: According to the budget.

- S2: We cut down some things. Expenditure or something.

- I: So [name], previously you won't set a budget to what you spend?

- S1: No. I didn't.

- I: So nowadays, you will set a budget to what you spend?

- S1:Yes.

- I: Okay, how do you go about doing your budget?

- S1: Like that loh.

I: $\$ 10$, \$8 spend, $\$ 2$ save? Alternatively, you have even more specific or better way of budgeting?

- S1: Like that, whatever you said.

- I: What did I say? [Name], how did you go about spending and saving your money now, after these few months of learning?

- S2: I still follow my method, I still use my budget. I keep a budget for a certain thing I want to buy.

- I: Any changes, previous and now? Any improvements in your budgeting?

- S2: Yeah, I started saving even more. 
- $\quad$ FGD-3-3

I: Can you share with me what do you understand by budget. Give me example, easier for you. So how do you budget?

- S1: To spend the money that I have in my control. Within my control.

- I: Can give me example whereby you spend the money in your control that's considered a budget?

- S1: Like I buy a birthday gift for my friend, I got $\$ 30$, then $\$ 30$ I left $\$ 10$ for myself, and then I use \$20 to buy a birthday present for my friend.

- I: The $\$ 20$ that you use is the budget?

- FGD-4-3

- It can be concluded that there is strong evidence of knowledge gains due to the FL intervention, and that these knowledge gains can to a certain extent translate into behavioral change.

Affective Dimension of FL: Importance of FL learning: The students generally showed positive attitudes towards FL and FL teaching and learning even before their exposure to the FL program:

I: Do u regard financial literacy as an important life skill?

- S1: yes, because for everyone there will come a time when one will not have enough money so u should learn about financial literacy.

- S2: Yes, because as you grow older, you might need money saved to but something that you want.

- S3: Yes because as u get older you may want to buy more things. Money saved can be used for the future.

- $\quad$ FGD-1

I: Do you think financial literacy is an important life skill?

- $[\ldots]$

- S1: Yeah.

- I: It is? Why is it so?

- S1: So that we know how to manage our money for future.

- I: For future, ok.

- S2: Yes.

I: Why?

- S2: Because maybe in the future after we get married must buy our own house, all like that. Then later if got babies, so many babies all, then can use the money. Save the money and buy clothes for the baby.

- I: Ok, alright

- S1: It's important so in the future we won't go to bankruptcy or something.

- $\quad$ FGD-2

This attitudinal trend was constant for all the three stages of the FL program:

I: Why do you think it's an important life skill?

- S1: Erm... if we did not save money...we have to beg for money.

- I: Oh really?

- S2: Beg yes. Because in the future when our parents are no more, we need to work for ourselves, find money, then we if we're married then we can support our family.

- FGD-1-2

I: Do you think that it's important to learn about managing money?

- S1: Yes, for the future.

- I: Any other thing than just your future?

- S1: Might buy a lot of things after getting married. 
- I: How young do you think one should start learning?

- S1: Now already.

- S1: Now is how old?

- V: $13,14$.

- $\quad$ FGD-4-3

Although attitudes towards FL were uniformly positive, attitudes to FL instruction were not. Typical misconceptions can be identified through a careful analysis of the qualitative data. First, some of the students do not consider FL useful for wealthy people. Second, many students consider FL a naturally acquired set of skills. Such misconceptions became transparent when the students discussed whether FL should be formally taught in a compulsory manner:

I: Do you think financial literacy should be made compulsory to all students?

- S1: No.

- I: Why?

- S1: Cause some of them are very rich. Therefore, they don't have to worry anything.

- I: So when they're very rich they don't have to worry about financial literacy, is it? Why is that so?

- S1: Their parents will plan everything for them.

- I: Oh, ok. What about you?

- S2: Yes, compulsory.

I: why?

- S2: 'Cause every kid will cannot always count on their parents to give money to them. They must work for a living.

- I: Ok, so financial literacy is important for all these students because they're going to work, they're

- $\quad[\ldots]$

- S3: Yeah, compulsory.

I: Why?

- S3: Even rich people must spend their money wisely, don't make their money go to waste.

- I: Ok alright.

- S4: Yes, because they must know how to use their money wisely.

- S5: No.

I: It's not compulsory. Why is it not compulsory?

- S5: It's like not everybody s interested in it.

- I: Not everybody is interested in wanting to learn about it, is it?

- S5: Yeah.

- $\quad$ FGD-2

At the same time, it is evident that not all of the students are equally susceptible to such misconceptions even in the pre-intervention phase. Surprisingly, the students showed more negative attitudes towards FL instruction at the outset of the program, as compared to the pre-intervention and post-intervention phases. These attitudes were a result of Meta cognitive reflection: the students have difficulty establishing the relevance of the factual FL knowledge acquired in the classroom to their everyday experience:

- S1: I learn the most is that, I do not understand money...

I: What do you mean?

- S1: And about financial literacy, because it is too complicated for me.

- FGD-1-2

I: So you...do you find the lessons interesting and fun for you?

- S1:Yah. 
- I: Yes, so do you learn something from it?

- S1: Yes.

- I: Yes. Okay.

- S2: No.

- I: Why no?

- S2: So boring.

I: Boring. In what way boring? No, it's honest, its honest, so why is it boring

- S2: I mean like they... teaches you on paper and all these ... are practicing towards ...for the person to go. In addition, they're all the same. Almost everything looks the same.

I: Okay so... then... how do you think you want to learn it?

- $\quad$ S2: By not learning it.

I: Learn it by not learning it? Why?

- S2: Not the time yet.

- $[\ldots]$

- S3: I only find it useful for the phone bill not under travel plan 'cause I don't even understand.

- FGD-2-2

Meta cognitive reflection on the goals and demands of a FL program also modulated value judgments in a positive direction. This process was gradual, with the most salient examples emerging in the postintervention FGDs:

I: do you consider financial literacy an important life skill? Part B will be, at what age do you think one should start to learn about financial literacy? So two parts okay. Is it important and at what age should one start.

- S1: Financial literacy is a very important skill. I think we should start it more on when we're old but start now.

- I: Start now.

- S1: Or even earlier.

I: Or even earlier. How old do you think it should be? The age?

- S1: Er, maybe primary three.

- I: Primary three. Okay. Primary three, to start to learn about money already.

- S1: Erm, because normally young we go out with parents for in market to buy groceries

I: Okay...

- S1: ...But in... not during this age... Students seldom go out with parents to buy.

- I: So you're saying that when they are young they normally follow the parents so that they can see how...

- $\quad$ S1: ... they can learn more.

I: Okay they can learn more... Alright thank you.

L: I'm L and I think that financial literacy is helpful also...

I: Okay then what age should one starts?

- S2: I don't think that at the age...At a young age like erm, primary one or yah...because... they like to spend on like toys like that...

- $\quad$ I: Uh uh, kiddy...

- S3: And like with financial literacy maybe it can help them to not spend too much.

- $\quad[\ldots]$

- S4: Erm, I think it's useful okay. It's important for our life. Therefore, I think we should start at around sixteen.

- I: Sixteen... 
- S4: Sixteen, seventeen.

- I: Uh um.

- S4: 'Cause we start... we can start to work already so then we can learn how to plan our money well.

- I: So you... think that only when you start to earn money than you need to start to learn about.... planning your money?

- S4: No because before you learn this... I'm sure the parents had teach the...their kids how to manage their money well.

- $\quad$ FGD-2-2

I: So the current program that you have in your school right, do you think that it's enough? Alternatively, do you think more can be done for you? That means the lesson that you have in your school now, the few lessons, do you think it's enough, or do you think there's still a lot more that the school or the teachers or anyone can do for you to help you learn more about it?

- S1: I think there's a lot more.

- I: When you say a lot more, how young do you think one should start to learn?

- S2: Now.

- I: Now, as in your age, now? 14 ?

- S2: Ya.

I: 14 years old is good enough, is it? Why do you think it's 14, and not any other age?

- S3: Start from young, instead of starting when we're like 20 or 19 years old.

- I: So you're thinking of young means in teens? Not even younger than teens.

- S3: Maybe for primary school kids they don't really understand but can still teach them the basics.

- I: So should start from primary school, let them be exposed to it, then when they're 14 years old, start to teach them something formally.

- S3: In more detail.

- FGD-2-3

This shows that the overall approach to teaching financial literacy aiming simultaneously at factual knowledge transfer, inducing attitude and, subsequently, behavioral change, is productive and beneficial for the students.

Table 1: The key findings of the qualitative study are summarized

\begin{tabular}{|c|c|c|}
\hline Theme & Pre-intervention & Post-intervention \\
\hline Cognitive dimension of FL & $\begin{array}{l}\text { Understanding of } \text { FL and } \\
\text { budgeting only in general } \\
\text { terms, sometimes } \\
\text { understanding at all }\end{array}$ & $\begin{array}{l}\text { Deeper understanding in terms of money } \\
\text { management skills, dynamics of } \\
\text { budgeting, can construct detailed } \\
\text { scenarios after the program had been } \\
\text { completed, tighter conceptual integration }\end{array}$ \\
\hline Affective dimension of FL & $\begin{array}{l}\text { Generally positive attitudes } \\
\text { towards FL and FL learning }\end{array}$ & $\begin{array}{l}\text { A J-shaped curve: less positive attitudes } \\
\text { to FL learning in the initial phase of the } \\
\text { program due to cognitive difficulties, } \\
\text { generally very positive attitudes in the } \\
\text { post-intervention phase }\end{array}$ \\
\hline Behavioral dimension of FL & $\begin{array}{l}\text { Self-reported reluctance to } \\
\text { engage in budgeting and } \\
\text { financial planning }\end{array}$ & $\begin{array}{l}\text { Gradual increase in self-reported } \\
\text { budgeting efficiency, acquisition of a less } \\
\text { short-term perspective regarding } \\
\text { financial planning }\end{array}$ \\
\hline
\end{tabular}

\section{Conclusion}

The study showed that FL program targeting a population of students from middle- and working-class social backgrounds helped the participants not only to acquire new knowledge but to go beyond passive knowledge acquisition to self-reflective contextualization of new skills and concepts. The study discovered desirable 
learning outcomes of the FL intervention both in factual learning and activation of underlying values, which emphasize financial self-reliance. It was also shown that cognitive, affective and behavioral dimensions of FL are inherently linked and form an organic whole. To summarize, a FL program informed by a constructivist approach to teaching and learning can arm the students with a means for successful socialization setting them on a path of life-long FL learning.

\section{References}

Adams, H. \& Wallace, B. (1989). Developing the potential of children in disadvantaged communities: The TASC Project - Thinking Actively in a Social Context. Paper presented at the 8th World Conference on Gifted and Talented Children, Sydney, Australia.

Jonassen, D. \& Tessmer, M. (1996/1997). An outcomes-based taxonomy for instructional systems design, evaluation and research. Training Research Journal, 2, 11-46.

Vygotsky, L. S. (1978). Mind and society: The development of higher psychological processes. Cambridge, MA: Harvard University Press.

Warr, D. J. (2005). It was fu. However, we don't usually talk about these things: Analyzing sociable interaction in focus groups. Qualitative Inquiry, 11, 200-224. 